\title{
PREVENTING DEATHS FROM COMPLICATIONS OF LABOUR AND DELIVERY
}

Eckhart J Buchmann FCOG(SA), MSc(Epidemiology), PhD

William Stones MD, FRCOG

Niranjan Thomas DCH, MD, DNB

\section{Corresponding author:}

Eckhart J Buchmann

Department of Obstetrics and Gynaecology

University of the Witwatersrand

Johannesburg

South Africa

Address: Department of Obstetrics and Gynaecology, Chris Hani Baragwanath Academic Hospital, PO Bertsham 2013, Johannesburg, South Africa

Email: eckhart.buchmann@wits.ac.za

Telephone: +27119338156; Mobile: +2711834087777

Fax: +27119381534

Co-authors:

William Stones

School of Medicine, University of St Andrews and College of Medicine, University of Malawi

Address: School of Medicine, University of St Andrews, Fife KY16 9JT, UK

Email: rws6@st-andrews.ac.uk

Telephone: +265994286077

Niranjan Thomas

Christian Medical College, Vellore

Address: Department of Neonatology, Christian Medical College, Vellore 632004, India

Email: niranjan@cmcvellore.ac.in

Telephone: +914162283312 


\section{ABSTRACT}

The process of labour and delivery remains an unnecessary and preventable cause of death for women and babies around the world. Although rates of maternal and perinatal death are declining, there are large disparities between rich and poor countries, and sub-Saharan Africa has not seen the scale of declines shown elsewhere. In many areas, maternity services remain sparse and underequipped, with insufficient and poorly trained staff. Priorities for reducing the mortality burden are provision of safe caesarean section, prevention of sepsis, and appropriate care of women in labour in line with current best practices, appropriately and affordably delivered. A concern is that largescale recourse to caesarean delivery has its own dangers and may present new dominant causes for maternal mortality. An area of current neglect is newborn care. However, innovative training methods and appropriate technologies offer opportunities for affordable and effective newborn resuscitation and follow-up management in low-income settings.

\section{KEY WORDS}

Maternal mortality; Perinatal mortality; Low-resource settings; Intrapartum care: Neonatal care 


\section{INTRODUCTION}

Until very recently in the evolution of our species, labour was a necessary event at the start of every human's life. Even with anticipation of the birth of a healthy baby to a happy mother, the possibility of serious hazard and death always lurked. This reality remains, even in modern childbirth facilities, but is especially pertinent in low- and middle-income countries (LMICs).

\section{MATERNAL AND PERINATAL DEATHS RELATED TO LABOUR AND DELIVERY}

\section{Burden of maternal deaths due to labour and delivery complications}

Labour and delivery play a role in just over one-third of maternal deaths worldwide $[1,2]$. In a recent systematic analysis for 2003-2009, the World Health Organization (WHO) estimated that 901000 deaths were labour-related ( $37 \%$ of maternal deaths globally), the causes being intrapartum haemorrhage (3\%), postpartum haemorrhage (53\%), sepsis (29\%), obstructed labour ( $8 \%$ ) and complications of labour (8\%)[1]. Over $99 \%$ of labour-related deaths occurred in developing countries. The overwhelming burden remains in sub-Saharan Africa and South Asia [3]. It is however encouraging that the Global Burden of Disease Study 2010 showed a 34\% decline from 137700 labour-related deaths in 1990 to 91100 in 2010 [2].

\section{Clinical causes of maternal deaths}

There are few studies with clinical detail on deaths from obstetric haemorrhage and sepsis. Possibly the best available data are South African triennial reports on confidential enquiries into maternal deaths [4]. The report for 2011-2013 includes 553 deaths from intrapartum and postpartum haemorrhage. The most frequent cause was bleeding at or after caesarean section in $40 \%$ of the deaths, followed by ruptured uterus with previous caesarean section (9\%), ruptured uterus without previous caesarean section (9\%), uterine atony after vaginal birth (9\%) and retained placenta (8\%) 
(Table 1). There were 205 deaths from puerperal sepsis, of whom $43 \%$ had caesarean sections. Caesarean section, traditionally the answer to the problem of labour-related death and injury, has become the chief cause of delivery-related maternal mortality in South Africa.

\section{Avoidable factors in maternal deaths}

Quality of care audits of adverse events reveal patient, system and health worker deficiencies. Merali et al. recently conducted a systematic review of audits of maternal deaths in LMICs [5]. Most of the audits were from sub-Saharan Africa. Recurring avoidable factors for labour-related maternal mortality were patient delay, blood transfusion problems, delay in care on admission to health facility, transport delay, delayed operative delivery, inadequate initial clinical management, and unavailability of health workers. Patient delay as an avoidable factor raised the issue, not only of access and finance, but also cultural factors and the need to involve families and communities in helping women to present for skilled care. New lessons on access emerged from a verbal autopsy study in Bangladesh, in an area where most births are still conducted by unskilled attendants [6]. The study found that primary care facilities were increasingly used by women, but were unable to respond with appropriate life-saving care. Health systems, previously underutilised, will need to meet the legitimate demand of women and families for emergency care that can prevent maternal deaths.

\section{Burden of perinatal deaths due to labour and delivery complications}

As with maternal mortality, about one-third of perinatal deaths (stillbirths and neonatal deaths) are related to labour and delivery $[7,8]$. Intrapartum-related perinatal deaths are always tragic and often avoidable, occurring mostly in well-grown term babies who are alive when labour starts [8]. Lawn et al. estimated that in 2008, there were 2.65 million stillbirths worldwide, of which 1.19 million (45\%) were intrapartum-related; $99.6 \%$ of intrapartum stillbirths occurred in LMICs. The intrapartum stillbirth rate for LMICs was 22 times greater than in high-income countries (9.4 vs. 0.43 per 1000 
births) [8]. A similar 24-fold difference was found for neonatal deaths between the richest and poorest countries (11.8 vs. 0.5 per 1000 live births) [9]. Liu et al. found that of 3.07 million neonatal deaths in 2010, 0.72 million (23\%) were intrapartum related. Good news was that the numbers of neonatal deaths fell between 2000 and 2010, by $2.4 \%$ annually worldwide. But Africa lagged behind the global average with only a $1.1 \%$ annual reduction in intrapartum-related deaths [7].

\section{Clinical causes of perinatal deaths}

There are different clinical pathways to intrapartum fetal hypoxia: 1) a condition pre-dating labour, for example pre-eclampsia, putting the baby at risk for hypoxia; 2) placental separation as in placental abruption or uterine rupture; 3) umbilical cord compression; 4) uterine contractions in prolonged or augmented labour; and 5) fetal entrapment causing hypoxia and/or physical injury [10]. Death may follow from hypoxic organ damage, meconium aspiration or infection [11]. A problem with published perinatal death data is a lack of clinical detail. A systematic review of 142 studies reporting causes of stillbirth found only patchy information [12]. A South African national audit from 102 facilities classified intrapartum-related deaths by clinical cause, the most frequent being 'intrapartum asphyxia' (67\%), followed by umbilical cord accidents $(23 \%)$, traumatic breech birth (5\%) and uterine rupture (3\%) (Table 1) [11].

\section{Avoidable factors in perinatal deaths}

The systematic review by Merali et al. also included avoidable factor audits of perinatal deaths [5]. The most frequent labour-related avoidable factors for perinatal deaths were patient delay, delay in care on admission to birth facility, delayed operative delivery, unavailability of health worker, and inadequate intrapartum monitoring of the fetus. To these can be added misuse of oxytocin [12], and neonatal resuscitation failures. Service provision assessments in six African countries in 2007 found that less than a quarter of hospital-born babies had access to neonatal resuscitation. There were serious equipment deficiciencies, with only a minority of staff appropriately trained [13]. 
<Insert Table 1 here>

\section{APPROACHES AND INTERVENTIONS TO PREVENT DEATHS RELATED TO LABOUR AND DELIVERY}

The commonality of avoidable factors in labour-related deaths illustrates that overall improvements in intrapartum care will prevent maternal deaths, intrapartum stillbirths and neonatal deaths [14].

\section{Safe caesarean delivery}

Improved accessibility to caesarean section is clearly needed, in line with recent 'Global Surgery 2030' advocacy [15]. But, as shown in the South African data, large scale recourse to caesarean delivery is not appropriate as the intervention itself carries significant harms [4]. By contrast, in highresource settings the safety of caesarean delivery is similar to that of vaginal birth, allowing guidelines to include 'maternal request' as an indication for surgery following appropriate counselling [16]. In low-resource settings the challenge is to extend access to caesarean delivery beyond the low levels currently found in population surveys, for example $4.6 \%$ for Malawi [17], while avoiding the excess morbidity and mortality seen in referral hospitals where caesarean delivery rates now approach 50\% [18]. Key clinical considerations for safe caesarean delivery are discussed below.

\section{Gestational age}

Timing of planned surgery depends on accurate knowledge of gestational age. Where early pregnancy sonography has confirmed the dates, it is possible almost completely to avoid newborn respiratory distress by scheduling the procedure for 39 weeks [19]. As the cost of ultrasound continues to fall, there is a need to develop systems to incorporate routine early pregnancy scanning into antenatal care. Implementation research is needed on training, staffing, referral systems, procurement and maintenance of obstetric ultrasound for low-resource settings, as well as critical 
study of the clinical impact. Correct dating also affects management of post-term pregnancy, where induction of labour may avoid late intrauterine fetal death and labour-related perinatal death [20].

\section{Safe Anaesthesia}

Anaesthetic complications accounted for a substantial proportion of maternal deaths reported in the United Kingdom until concerted efforts were made to ensure adequacy of equipment, staffing and pre-operative preparation. A commentator noted a decade ago that "anaesthesia for caesarean section in the UK is now 30 times safer than it was in the 1960s" [21]. An insight into the multiple components that need to be in place to assure optimally safe obstetric anaesthesia is provided by the exhaustive listing of the Royal College of Anaesthetists [22]. Many facilities in LMICs will find these standards difficult to meet.

\section{Subsequent pregnancies}

Concern about increasing caesarean section rates includes subsequent pregnancy outcome, such as placenta praevia or accreta leading to major haemorrhage and risk of obstetric hysterectomy. It is estimated that 359 caesarean deliveries at first birth result in one additional case of placenta praevia among the next pregnancies [23]. With regard to uterine scar rupture in subsequent trials of labour, while guidelines typically quote risks of around 1:200 after one, and 1:50 after two caesarean sections, there is concern about the ability to undertake adequate intrapartum monitoring and mount a rapid response if scar dehiscence is suspected in low-resource settings [24].

\section{Surgical workforce}

The cadre of surgeon is probably less important than the specific competencies of individual practitioners. The role of surgical technicians or clinical officers has been the subject of systematic review and while there were no differences in maternal and perinatal mortality following procedures done by clinical officers versus physicians, there was a greater risk of wound sepsis and dehiscence 
among the former [25]. The possible link between surgical skill and wound sepsis is hard to pin down in formal studies, but the excess of wound dehiscence may be explained by frequent use of midline vertical sub-umbilical incisions by non-physician surgeons. Surgical training should emphasise the transverse approach to mitigate this problem. Non-physician providers remain critically important for extending access to surgery [26]. Regarding cadre of anaesthesia provider, a Cochrane review could not generate informative conclusions [27]. In any event, the comparison is theoretical, considering the small numbers of physician anaesthetists practicing in the developing world, especially in sub-Saharan Africa. Where present, such practitioners are likely to be in leadership roles or supporting complex surgical and critical care, and would not be available as primary obstetric anaesthesia providers.

\section{Sepsis related to labour and delivery}

Common challenges include failure to use established best practice, whether antibiotics for prelabour rupture of the membranes or routine prophylactic antibiotic at caesarean section. While recent widespread uptake of antiretrovirals in regions of high HIV prevalence has reduced the burden of sepsis associated with immunosuppression, there is a real risk of recrudescence of puerperal sepsis owing to deficient hygiene and antibiotic resistance [28]. Effective care for women with severe sepsis requires early recognition, often a challenge in previously healthy women who are much sicker than is realised. Microbiology and rapid clinical chemistry backup is absent in many settings, so indirect tools such as the white cell count may be the limit of available investigations.

\section{Fetal intrapartum hypoxia and birth trauma}

Life-threatening fetal hypoxia in labour is likely preceded by a period of detectable fetal distress, with fetal heart decelerations associated with tachycardia, or later bradycardia. Routine fetal monitoring should allow detection of fetal distress. Cardiotocography (CTG) is not the answer, as it increases the likelihood of caesarean delivery while providing no benefit to the baby [29]. 
Intermittent auscultation every 15 minutes in the active phase of the first stage, and every 5 minutes in the second stage, is currently recommended in the International Federation of Gynecology and Obstetrics (FIGO) 2015 guidelines [30]. CTG should be reserved for high-risk labour, for example in association with pre-eclampsia, induction of labour, prolonged labour, or where fetal distress is suspected on auscultation. The response to fetal distress may be intrauterine resuscitation, assisted vaginal birth, or caesarean section. Clear systematic documentation, for example presented on a partograph, cannot be over-emphasised [31].

Intrapartum fetal emergencies include severe fetal distress (from cord prolapse, placental abruption, uterine tachysystole, and ruptured uterus) as well as entrapment disorders, like shoulder dystocia and difficult breech birth. Randomised trials do not exist to guide the management of these conditions in terms of saving babies' lives, but numerous guidelines, based mainly on clinical experience, are available to assist midwives and physicians with management algorithms. The important point is that all obstetric clinicians must be ready to deal with these catastrophic events at any time. Current evidence suggests that the best way to stay skilled and up-to-date is in performing regular drills (simulation training) in the labour ward. [32,33]. All that is required in the maternity facilities is leadership to ensure that the drills are done, with the necessary simulation models at hand.

Risks associated with childbirth and approaches to mitigation in low-resource settings are summarised in Table 2. Risks related to haemorrhage and hypertensive disease are covered in chapters 6 and 7 respectively

<Insert Table 2 here>

\section{Functional maternity units}


A key challenge for maternity care professionals is balancing the need for woman-centred humanistic care with rapid detection and response to life-threatening complications. Our ability to predict complications is limited: most high-risk women do not in fact suffer complications, while most complications occur in low-risk women. To translate these dual requirements into physical facilities, staffing levels and skills mix, and service protocols and guidelines, is challenging. Typical barriers include: 1) separation of professional groups where midwives do not co-ordinate care with physicians; 2) separation between academic and service lines of accountability, where training content differs significantly from the way services are actually provided [34]; and 3) gaps in inservice maintenance of practical competencies, for example in not doing emergency obstetrics drills. A critical test is what actually happens during the second stage of labour: are women encouraged to adopt a position of their choice, is their companion encouraged to stay with them, and is maternal and fetal monitoring maintained so that fetal bradycardia can be detected and acted upon immediately? To achieve this requires not one but two skilled attendants [35], and by extension a model of labour ward organisation that can flexibly allocate staff, responding to changes in clinical states of particular patients, and also to peaks and troughs in demand.

\section{Configuration of services for 'very sick obstetric patients'}

Often the capacity to manage a very sick patient in the normal labour ward is limited. In referral hospitals, intensive care units (ICUs) are often fully utilised, and within the typical ICU setting obstetric patients form a small proportion of the case mix [36]. Most very sick obstetric patients, mainly those with eclampsia, major haemorrhage or severe sepsis, do not require mechanical ventilation or inotropic support. Close observation and support of organ function through blood pressure control and seizure prevention, pulse oximetry, oxygen administration, management of fluid balance, blood replacement and parenteral antibiotic therapy are the main elements of care. This level of care can be efficiently provided in a high dependency unit (HDU) configuration, with a 1:2 or better nursing ratio. A physical location close to the postnatal area facilitates mother-baby 
contact and breast feeding. Nursing administrative arrangements are essential for smooth 'step up' of care for patients who deteriorate and need ICU transfer, and 'step down' care for those ready for transfer to a postnatal ward. Such arrangements mean that a limited number of HDU beds can be used with high occupancy and rapid turnover. Currently, there are no standard definitions of eligibility and exact service configuration for obstetric HDU care, but experience from Aberdeen over 23 years is a good starting point, describing an approach that combines 'high tech' monitoring with a 'mother and baby friendly' environment [37].

\section{Costs and sustainability of complex care}

As public health initiatives to encourage facility-based childbirth under the care of skilled birth attendants gain traction, health systems need to prepare for the care needs of mothers and newborns who might have succumbed to complications in the community but are now brought into hospital. These may be very sick patients requiring complex care and may need to be managed in HDU or ICU facilities. In terms of costing, a small proportion of births will be associated with lifethreatening complications, and service planning models should factor in this inevitable burden of complex cases. Where free maternity care is provided through state or other mandated provision, 'free' also needs to include complex care when needed, with reimbursement to providers that is adequate to provide a functional life-saving service.

\section{NEWBORN CARE}

Management of babies with perinatal asphyxia consists of immediate, adequate and appropriate resuscitation, supportive post-resuscitation measures and neuroprotective strategies where feasible. Guidelines for neonatal resuscitation have recently been published (Figure 1). [38,39]. Some of these guidelines may not be feasible in. However, every birth should be attended by at least one person who can perform the initial steps and provide effective positive pressure ventilation (PPV). More 
than $95 \%$ of newborns can be managed at birth with basic resuscitation skills $[40,41]$. A narrative summary of the new neonatal resuscitation guidelines, with follow-up care, is presented here.

\section{Newborn resuscitation}

\section{Initial Steps}

Non-vigorous newborns born through meconium- stained fluid should not be routinely intubated for tracheal suctioning. Delay cord clamping for at least 30-60 seconds for vigorous newborns [38,39]. Start resuscitation $\geq 35$ weeks' gestation with room air ( $21 \%$ oxygen). For infants at $<35$ weeks, start with $21-30 \%$ oxygen [38,39]. In low-resource settings where blended oxygen is not available, start with room air. If the baby's heart rate $(H R)$ is $<60 /$ min after 90 seconds of resuscitation, increase free-flow oxygen to $100 \%$ until recovery of a normal heart rate [42]. If breathing is laboured or oxygen saturation $\left(\mathrm{SpO}_{2}\right)$ cannot be maintained, start a trial of continuous positive airway pressure (CPAP) $[38,39]$. If a pulse-oximeter is not available, improvement in HR or colour may be used for assessment.

\section{Positive pressure ventilation and chest compressions}

The most important component of neonatal resuscitation is PPV, which should be started within 1 minute of birth - 'the first golden minute' [43]. After completing the initial steps, start PPV if the baby is apnoeic or gasping or the $\mathrm{HR}<100 /$ minute, or if $\mathrm{SpO}_{2}$ cannot be maintained. Use a flow rate of $10 \mathrm{~L} / \mathrm{min}$ with initial ventilation pressure of $20-25 \mathrm{~cm} \mathrm{H}_{2} \mathrm{O}$. For PPV in a preterm newborn, use a device that can provide PEEP (positive end-expiratory pressure). The most important indicator of successful PPV is a rising HR. Endotracheal intubation is recommended before beginning chest compressions. If intubation is not successful or feasible, a laryngeal mask airway can be used [38,39]. If the HR remains $<60 /$ min after 30 seconds of effective PPV, start chest compressions with PPV at a 
ratio of $3: 1$ and $\mathrm{FiO}_{2}$ at $100 \%$ until the $\mathrm{HR}$ improves. Use the two-thumb technique for compressions and continue for 60 seconds before re-checking the HR.

If there is no detectable $H R$ after 10 minutes of resuscitation, or where $H R$ is $<60 /$ min with no spontaneous breathing after 20 minutes, resuscitation should be discontinued in view of high risks of mortality or severe neurodevelopmental morbidity [43].

\section{Medication}

Epinephrine is indicated if HR remains $<60$ min only after at least 30 seconds of PPV that inflates the lungs AND another 60 seconds of chest compressions with PPV using 100\% oxygen. Give one endotracheal dose of epinephrine while awaiting vascular access. If this dose does not bring a satisfactory response, give a repeat dose as soon as umbilical venous catheter (UVC) or intra-osseous access is obtained. For hypovolaemia, use $0.9 \%$ saline (not Ringer-Lactate) or type-0 Rh-negative blood. There is no evidence for routine use of sodium bicarbonate or naloxone $[38,39]$.

Thermal management for babies born preterm: The temperature in the room where resuscitation occurs should be $23-25^{\circ} \mathrm{C}$. The goal is an axillary temperature of $36.5-37.5^{\circ} \mathrm{C}$. At $<32$ weeks gestational age, additional interventions, such as plastic wrap, thermal mattress and/or hat, are recommended $[38,39]$. Plastic bags have been shown in low-resource settings to be useful in preventing hypothermia even in term babies [44].

<Insert Figure 1 here>

\section{Post-resuscitation care}

Standard intensive care is critical in the management of infants with hypoxic-ischaemic encephalopathy (HIE). Management of multi-organ dysfunction, and of acid-base, hemodynamic and 
electrolyte balance, as well as seizure control can prevent further damage to the brain and improve neurodevelopmental outcome (Table 3).

Ventilation and oxygenation: Many of these sick newborns require ventilation. While hypoxemia disturbs cerebral autoregulation, increasing the risk of ischemia, hyperoxia increases neuronal injury through cerebral vasoconstriction and oxidative stress. Hypercarbia causes cerebral vasodilatation and intracranial hemorrhage, and worsens neuronal intracellular acidosis, while hypocarbia causes cerebral vasoconstriction. In a study adjusting for the severity of birth asphyxia, peak $\mathrm{PaO}_{2}$ values $>200 \mathrm{mmHg}$ in the first $20-120$ minutes of life and trough $\mathrm{PaCO}_{2}$ values $<20 \mathrm{mmHg}$ were significantly associated with adverse outcomes [45]. Hence, oxygen supplementation and ventilation should be rigorously controlled.

Cardiac dysfunction: Hypoxia-induced cardiac injury may manifest as hypotension [46]. Avoiding hypotension is important because of pressure passive cerebral circulation in asphyxiated neonates [47]. If echocardiographic assessment indicates adequate cardiac contractility but evidence of hypovolaemia, consider a normal saline bolus $(10-20 \mathrm{~mL} / \mathrm{kg})$, or blood transfusion if the hematocrit is $<30 \%$. Start inotropes if echocardiographic assessment indicates poor contractility or if blood pressure remains low despite volume replacement.

Fluid, electrolytes and glucose: Infants with HIE often develop fluid overload presenting with edema, oliguria and hyponatremia. This may be due to acute tubular necrosis, syndrome of inappropriate anti-diuretic hormone release or use of fluid boluses. Electrolyte disturbances like hypocalcaemia and hypomagnesaemia are common and should be managed appropriately. Both hypoglycemia and hyperglycemia accentuate neuronal injury $[48,49]$. 
Coagulopathy and other organ injury: Disseminated intravascular coagulation may occur and require treatment with blood component transfusion [50]. Renal dysfunction due to acute tubular necrosis is usually transient and resolves in the first week [51]. Liver damage manifests as elevated transaminases and may exacerbate coagulation problems [52]. Early aggressive enteral feeding should be avoided as this may precipitate necrotizing enterocolitis [53].

Treatment of seizures: Seizures are associated with accelerated cerebral metabolism, leading to a fall in brain glucose, with increased lactate and decreased ATP. Seizures are also associated with hypoventilation with consequent hypoxemia and hypercarbia. Repeated seizures increase the extent of neuronal injury as well as the risk of subsequent epilepsy [54-56]. Phenobarbitone and phenytoin are the commonly used anticonvulsants [57]. The drugs given together are effective in suppressing only just more than $50 \%$ of the seizures. Alternative drugs include benzodiazepines and lignocaine. Newer anticonvulsants like topiramate and levetiracetam are not yet adequately studied in newborns, although there are reports of levetiracetam being used effectively [58]. Continuous EEG studies show that an electrographic seizure burden often remains after anticonvulsant treatment $[59,60]$. Whether treating all electrographic seizures is necessary is unclear, as both the seizure burden and the use of anticonvulsant drugs adversely influence neurodevelopmental outcome $[61,62]$. Anticonvulsants can usually be stopped before discharge especially regarding concern on effects of anticonvulsants on the immature brain [63].

\section{<Insert Table 3 here $>$}

\section{Neuroprotection}

With progress in understanding neurochemical events that mediate brain damage after hypoxicischemic insults, new treatment strategies have evolved, principal of which is hypothermia. Other neuroprotective strategies are still undergoing research [64]. 
Therapeutic Hypothermia (TH): TH has been shown to reduce the severity of HIE-associated secondary reperfusion brain injury. Cooling acts at various levels of the neuronal injury cascade, reducing cerebral energy utilization, attenuating excitotoxic injury, and inhibiting apoptosis, free radical production and the inflammatory cascade [65]. A Cochrane review has shown significant reduction in mortality or neurodevelopmental disability at 18 months [66]. The efficacy of TH in lowresource settings is unproven, and may be reduced because of inefficiency of the cooling devices, suboptimal intensive care, or intrinsic differences in the populations served $[67,68]$. While studies from LMICs have established the safety and feasibility of TH in intensive care settings $[69,70]$, a meta-analysis of randomized trials from LMICs, including 567 infants, showed no significant reduction in neonatal mortality ( $\mathrm{RR} 0.74 ; 95 \% \mathrm{Cl} 0.44-1.25$ ) [71]. However, the confidence intervals were wide, with the effect size compatible with results from high-income countries. Recent systematic review suggests that low-technology cooling methods are feasible in a LMIC intensive care setting [72,73].

Criteria for $\mathrm{TH}$ are moderate or severe encephalopathy, age $<6$ hours, gestational age $\geq 36$ weeks (or $1800 \mathrm{~g}$ ), and either 10-minute Apgar score $<5$, Need for resuscitation $\geq 10$ minutes, or cord $\mathrm{pH}<7$ or cord base deficit $>16 \mathrm{mmol} / \mathrm{L}$. The earlier cooling is commenced, the better the outcome, as the therapeutic window reduces with increasing severity of injury. The core temperature is maintained at $33.5^{\circ} \mathrm{C}\left(33-34^{\circ} \mathrm{C}\right)$ for 72 hours, followed by slow rewarming at $0.2-0.5^{\circ} \mathrm{C} /$ hour.

\section{Neonatal resuscitation training programs}

Two global training programs on neonatal resuscitation, Neonatal Resuscitation Program (NRP) and Helping Babies Breathe (HBB) are initiatives of the American Academy of Pediatrics in collaboration with WHO and other global health organizations. While NRP deals with training hospital health care workers in advanced resuscitation, HBB trains first-level birth attendants in basic resuscitation using 
simplified algorithms and culturally sensitive pictorial-based learning materials. Large trials conducted in Tanzania have shown that neonatal mortality at 24 hours decreased by more than onethird after implementing HBB training of local midwives $[33,74]$. However, neonatal training coverage remains low in the regions where most neonatal deaths due to asphyxia occur. Universal regular training of health care workers under NRP and HBB would be a valuable step for achieving the Every Newborn Action Plan target of reducing the neonatal mortality rate to $<10$ per 1000 live births by 2035 .

\section{Conflict of interests}

The authors declare no conflicts of interest. 


\section{SUMMARY}

Labour and delivery still cause unacceptably high maternal and perinatal mortality, especially in South Asia and sub-Saharan Africa. With increased community demand, improved infrastructure and better utilisation of services, maternity care facilities are now challenged to provide safe and quality care for women in labour and at delivery. This includes safe caesarean section and anaesthesia, where the operation is clinically indicated. Trained and certified non-physician surgeons and anaesthetists offer a rapid path to greater access to safe caesarean section in low-resource settings. Care of women in labour requires adherence to well-established evidence-based best practices, adjusted for local circumstances. Examples are partograph use, close maternal and fetal monitoring in labour, and correct management of life-threatening obstetric emergencies.

A reconfiguration of health systems is needed, to provide functional maternity units, balancing respectful woman-centred quality care with technically competent life-saving capabilities. There is growing acceptance that emergency obstetric and newborn care drills are the best way to maintain the necessary skills among obstetric clinicians. Particular attention must be given to establishing obstetric maternal high-dependency units, to care for very sick obstetric patients, who are at high risk of death. Such units must be accessible to all women, including the indigent and those who have suffered labour complications outside the formal health system. And there is little excuse now for failures to deliver high-quality newborn care in health facilities. Neonatal care innovations, including novel training approaches, have made it possible to provide effective resuscitation and follow-up care, including therapeutic hypothermia, in low-resource settings. 


\section{HIGHLIGHTS}

- There are still large rich-poor global disparities in labour-related mortality rates

- Better access to safe caesarean section carries great promise, with risks attached

- Regular emergency obstetric drills are indispensable elements of in-service training

- Low-resource services must prioritise functional maternity units to save lives

- Training and practice innovations can reverse the current neglect of newborn care

\section{PRACTICE POINTS}

- Balance woman-centred respectful care in labour with appropriate technological monitoring and intervention according to current best practice

- Establish obstetric high-dependency units within functional maternity units

- Establish regular obstetric emergency simulation drills to inject and maintain skills in the clinical staff

- In low-resource areas, it is reasonable and affordable to prioritise neonatal resuscitation and follow-up care, possibly including therapeutic hypothermia

\section{RESEARCH AGENDA}

- Response of cause-specific mortality rates to improvements in intrapartum services and care

- Optimal configuration of high-dependency obstetric care in low-resource settings

- Health care financing models for maternity services that incorporate the cost of complex care

- Use of sustained breaths to provide FRC in neonatal resuscitation\

- New education methods to improve neonatal resuscitative efforts in low- and middle-income countries 


\section{REFERENCES}

1. Say L, Chou D, Gemmill A, et al. Global causes of maternal death: a WHO systematic analysis. Lancet Glob Health 2014;2:e323-33.

*2. Lozano R, Naghavi M, Foreman K, et al. Global and regional mortality from 235 causes of death for 20 age groups in 1990 and 2010: a systematic analysis for the Global Burden of Disease Study 2010. Lancet 2012;380:2095-128.

3. Ronsmans C, Graham WJ, on behalf of The Lancet Maternal Survival Series steering group. Maternal mortality: who, when, where and why. Lancet 2006;368:1189-200.

*4. National Committee for Confidential Enquiry into Maternal Deaths. Saving Mothers 2011-2013: Sixth report on the Confidential Enquiries into Maternal Deaths in South Africa. Pretoria: Department of Health, 2015.

5. Merali H, Lipsitz S, Hevelone N, et al. Audit-identified avoidable factors in maternal and perinatal deaths in low resource settings: a systematic review. BMC Pregnancy and Childbirth 2014;14:280.

6. Halim A, Utz B, Biswas A, et al. Cause of and contributing factors to maternal deaths; a crosssectional study using verbal autopsy in four districts in Bangladesh. BJOG 2014;121(Suppl 4):86-94.

7. Liu L, Johnson H, Cousens S, et al. Global, regional and national causes of child mortality: an updated systematic analysis for 2010 with time trends since 2000. Lancet 2012;379:2151-61. 
8. Lawn JE, Blencowe H, Pattinson R, et al. Stillbirths: Where? When? Why? How to make the data count? Lancet 2011;377:1448-63.

9. Lawn JE, Lee ACC, Kinney M, et al. Two million intrapartum-related stillbirths and neonatal deaths: Where, why and what can be done? Int J Gynecol Obstet 2009;107:S5-19.

*10. Wall SN, Lee AC, Carlo W, et al. Reducing intrapartum-related neonatal deaths in low- and middle-income countries - what works? Semin Perinatol 2010;34:395-407.

11. The MRC unit for Maternal and Infant Health Care Strategies, PPIP Users and the National Department of Health. Saving Babies 2003: Fourth perinatal care survey of South Africa. Pretoria: MRC Unit for Maternal and Infant Health Care Strategies, 2004.

12. Aminu M, Unkels $R$, Mdegela $M$, et al. Causes of and factors associated with stillbirth in low- and middle-income countries: a systematic literature review. BJOG 2014;121(Suppl 4):141-53.

13. Wall SN, Lee AC, Niermeyer S, et al. Neonatal resuscitation in low-resource settings: What, who and how to overcome challenges to scale up? Int J Gynecol Obstet 2009;107:S47-64.

14. Blencowe H \& Cousens S. Addressing the challenge of neonatal mortality. Trop Med Int Health 2013;18:303-12.

*15. Meara JG, Leather AJM, Hagander L, et al. Global Surgery 2030: evidence and solutions for achieving health, welfare and economic development. Lancet 2015;386:569-624. 
16. NICE 2011. Caesarean section: NICE guidelines [CG132], November 2011. Available at http://www.nice.org.uk/guidance/cg132/chapter/1-recommendations (accessed 28 December 2015).

17. National Statistical Office (NSO) and ICF Macro. 2011. Malawi Demographic and Health Survey 2010. Zomba, Malawi, and Calverton, Maryland, USA: NSO and ICF Macro.

18. Litorp H, Kidanto HL, Rööst M, et al. Maternal near-miss and death and their association with Caesarean section complications: a cross-sectional study at a university hospital and a regional hospital in Tanzania. BMC Pregnancy Childbirth 2014;14:244.

19. Joint Commission. Measure Information Form PC-01 Elective Delivery. In: Specifications Manual for Joint Commission National Quality Measures (v2013A1). Available at: https://manual.jointcommission.org/releases/TJC2013A/MIF0166.html (accessed 28 December 2015).

20. Gülmezoğlu AM, Crowther CA, Middleton P, et al. Induction of labour for improving birth outcomes for women at or beyond term. Cochrane Database Syst Rev 2012;6:CD004945.

21. Ngan Kee WD. Confidential Enquiries into Maternal Deaths: 50 years of closing the loop. Br J Anaesth 2005;94: 413-416.

22. Mushambi MC \& Plaat FS. Chapter 9: Guidance on the provision of obstetric anaesthesia services 2015. In: Venn PJ (Editor). Guidelines for the provision of anaesthetic services 2015. Royal College of Anaesthestists, London ISBN 978-1-900936-10-1 Available at: 
23. Gurol-Urganci I, Bou-Antoun S, Lim CP, et al. Impact of Caesarean section on subsequent fertility: a systematic review and meta-analysis. Human Reproduction 2013;28: 1943-52.

24. Wanyonyi SZ \& Ngichabe SK. Safety concerns for planned vaginal birth after caesarean section in sub-Saharan Africa. BJOG 2014;121:141-4.

25. Wilson A, Lissauer D, Thangaratinam S, et al. A comparison of clinical officers with medical doctors on outcomes of caesarean section in the developing world: meta-analysis of controlled studies. BMJ 2011;342:d2600.

26. FIGO Safe Motherhood and Newborn Health Committee. Human resources for health in the lowresource world: collaborative practice and task shifting in maternal and neonatal care. Int J Gynecol Obstet 2009;105:74-6.

27. Lewis SR, Nicholson A, Smith AF, et al. Physician anaesthetists versus non-physician providers of anaesthesia for surgical patients. Cochrane Database Syst Rev. 2014;7:CD010357.

28. Graham W J, Dancer SJ, Gould IM, et al. Childbed fever: history repeats itself? BJOG 2015;122;2:156-9.

29. Alfirevic Z, Devane D \& Gyte GML. Continuous cardiotocography (CTG) as a form of electronic fetal monitoring (EFM) for fetal assessment during labour. Cochrane Database Syst Rev 2013;5:CD006066. 
30. Lewis D \& Downe S. FIGO consensus guidelines on intrapartum fetal monitoring: intermittent auscultation. Int J Gynecol Obstet 2015;131:9-12.

31. Lavender T, Hart A \& Smyth RM. Effect of partogram use on outcomes for women in spontaneous labour at term. Cochrane Database Syst Rev 2013;7:CD005461.

*32. Berg AM, Baloyi S \& Pattinson RC. What is the impact of multi-professional obstetric and neonatal care training? Best Pract Res Clin Obstet Gynaecol 2015;29:1028-43.

33. Mduma $\mathrm{E}$, Ersdal $\mathrm{H}$, Svensen $\mathrm{E}$, et al. Frequent brief on-site simulation training and reduction in 24-h neonatal mortality--an educational intervention study. Resuscitation. 2015;93:1-7.

*34. Stones W \& Arulkumaran S. Health-care professionals in midwifery care. Lancet 2014;384:116970.

35. FIGO Safe Motherhood and Newborn Health (SMNH) Committee. Management of the second stage of labor. Int J Gynecol Obstet 2012;119:111-6.

36. Githae F, Mung'ayi V \& Stones W. Course and outcome of obstetric patients admitted to a university hospital Intensive Care Unit. E Afr Medical J 2011;88:356-60.

*37. Saravanakumar K, Davies L, Lewis M, et al. High dependency care in an obstetric setting in the UK. Anaesthesia 2008; 63: 1081-1086. 
*38. PerIman JM, Wyllie J, Kattwinkel J, et al. Part 7: Neonatal resuscitation 2015 international consensus on cardiopulmonary resuscitation and emergency cardiovascular care science with treatment recommendations. Circulation 2015;132(16 suppl 1):S204-41.

39. Wyckoff MH, Aziz K, Escobedo MB, et al. Part 13: Neonatal resuscitation 2015 American Heart Association Guidelines update for cardiopulmonary resuscitation and emergency cardiovascular care. Circulation. 2015;132(18 suppl 2):S543-60.

40. Ersdal HL, Mduma E, Svensen E, et al. Early initiation of basic resuscitation interventions including face mask ventilation may reduce birth asphyxia related mortality in low-income countries: a prospective descriptive observational study. Resuscitation 2012;83:869-73.

41. Perlman JM, \& Risser R. Cardiopulmonary resuscitation in the delivery room. Associated clinical events. Arch Pediatr Adolesc Med 1995;149:20-5.

42. Ramji S, Bhat S, Jain S, et al. Neonatal Resuscitation: India. 2nd ed. New Delhi: National neonatology forum of India, 2014.

*43. World Health Organization. Guidelines on basic newborn resuscitation. Available at: http://www.ncbi.nlm.nih.gov/books/NBK137872/ (accessed 14 December 2015).

44. Belsches TC, Tilly AE, Miller TR, et al. Randomized trial of plastic bags to prevent term neonatal hypothermia in a resource-poor setting. Pediatrics. 2013;132:e656-61.

45. Klinger G, Beyene J, Shah P, et al. Do hyperoxaemia and hypocapnia add to the risk of brain injury after intrapartum asphyxia? Arch Dis Child Fetal Neonatal Ed. 2005;90:F49-52. 
46. Armstrong K, Franklin O, Sweetman D, et al. Cardiovascular dysfunction in infants with neonatal encephalopathy. Arch Dis Child 2012;97:372-5.

47. Yoshida-Shuto H, Yasuhara A \& Kobayashi Y. Cerebral blood flow velocity and failure of autoregulation in neonates: their relation to outcome of birth asphyxia. Neuropediatrics $1992 ; 23: 241-4$.

48. Salhab WA, Wyckoff MH, Laptook AR, et al. Initial hypoglycemia and neonatal brain injury in term infants with severe fetal acidemia. Pediatrics 2004;114:361-6.

49. Spies EE, Lababidi SL \& McBride MC. Early hyperglycemia is associated with poor gross motor outcome in asphyxiated term newborns. Pediatr Neurol 2014;50:586-90.

50. Bauman ME, Cheung P-Y \& Massicotte MP. Hemostasis and platelet dysfunction in asphyxiated neonates. J Pediatr 2011;158(2 Suppl):e35-9.

51. Gupta BD, Sharma P, Bagla J, et al. Renal failure in asphyxiated neonates. Indian Pediatr $2005 ; 42: 928-34$.

52. Choudhary M, Sharma D, Dabi D, et al. Hepatic dysfunction in asphyxiated neonates: prospective case-controlled study. Clin Med Insights Pediatr 2015;9:1-6.

53. Christensen RD, Lambert DK, Baer VL, et al. Necrotizing enterocolitis in term Infants. Clin Perinatol 2013;40:69-78. 
54. Shah DK, Wusthoff CJ, Clarke $P$, et al. Electrographic seizures are associated with brain injury in newborns undergoing therapeutic hypothermia. Arch Dis Child Fetal Neonatal Ed 2014;99:F219-24.

55. Glass HC, Glidden D, Jeremy RJ, et al. Clinical Neonatal Seizures are Independently Associated with Outcome in Infants at Risk for Hypoxic-Ischemic Brain Injury. J Pediatr 2009;155:318-23.

56. Rodriguez-Alvarez N, Jimenez-Mateos EM, et al. Effects of hypoxia-induced neonatal seizures on acute hippocampal injury and later-life seizure susceptibility and anxiety-related behavior in mice. Neurobiol Dis 2015;83:100-14.

57. Booth D \& Evans DJ. Anticonvulsants for neonates with seizures. Cochrane Database Syst Rev 2004;4:CD004218.

58. Mruk AL, Garlitz KL, Leung NR. Levetiracetam in Neonatal Seizures: A Review. J Pediatr Pharmacol Ther JPPT. 2015;20(2):76-89.

59. Glass HC, Wusthoff CJ, Shellhaas RA, et al. Risk factors for EEG seizures in neonates treated with hypothermia: a multicenter cohort study. Neurology. 2014 Apr 8;82(14):1239-44.

60. Wietstock SO, Bonifacio SL, Sullivan JE, et al. Continuous video electroencephalographic (EEG) monitoring for electrographic seizure diagnosis in neonates: a single-center study. J Child Neurol 2015 Jun 30. pii: 0883073815592224.

61. Srinivasakumar P, Zempel J, Trivedi S, et al. Treating EEG seizures in hypoxic ischemic encephalopathy: a randomized controlled trial. Pediatrics 2015;136:e1302-9. 
62. Maitre NL, Smolinsky C, Slaughter JC, et al. Adverse neurodevelopmental outcomes after exposure to phenobarbital and levetiracetam for the treatment of neonatal seizures. J Perinatol Off J Calif Perinat Assoc 2013;33:841-6.

63. Volpe J. Neonatal seizures. In: Volpe J. Neurology of the newborn. 6th ed. Canada: Elsevier;2008:203-37.

64. Wu Q, Chen W, Sinha B, et al. Neuroprotective agents for neonatal hypoxic-ischemic brain injury. Drug Discov Today 2015;20:1372-81.

65. Drury PP, Gunn ER, Bennet L, et al. Mechanisms of hypothermic neuroprotection. Clin Perinatol 2014;41:161-75.

66. Jacobs SE, Berg M, Hunt R, et al. Cooling for newborns with hypoxic ischaemic encephalopathy. Cochrane Database Syst Rev 2013;1:CD003311.

67. Galvao TF, Silva MT, Marques MC, et al. Hypothermia for perinatal brain hypoxia-ischemia in different resource settings: a systematic review. J Trop Pediatr 2013 Dec;59:453-9.

68. Montaldo P, Pauliah SS, Lally PJ, et al. Cooling in a low-resource environment: lost in translation. Semin Fetal Neonatal Med 2015;20:72-9.

69. Thomas N, George KC, Sridhar S, et al. Whole body cooling in newborn infants with perinatal asphyxial encephalopathy in a low resource setting: a feasibility trial. Indian Pediatr 2011;48:445-51. 
70. Robertson NJ, Nakakeeto M, Hagmann C, et al. Therapeutic hypothermia for birth asphyxia in low-resource settings: a pilot randomised controlled trial. Lancet 2008;372:801-3.

71. Pauliah SS, Shankaran S, Wade A, et al. Therapeutic hypothermia for neonatal encephalopathy in low- and middle-income countries: a systematic review and meta-analysis. PloS One. 2013;8:e58834.

*72. Rossouw G, Irlam J \& Horn AR. Therapeutic hypothermia for hypoxic ischaemic encephalopathy using low-technology methods: a systematic review and meta-analysis. Acta Paediatr 2014 Oct 18. doi: 10.1111/apa.12830.

73. RHL. The WHO Reproductive Health Library. Cooling for newborns with hypoxic ischaemic encephalopathy. Available at: www.apps.who.int/rhl/newborn/cd003311 ballotde com/en/ (accessed 23 December 2015).

74. Msemo G, Massawe A, Mmbando D, et al. Newborn mortality and fresh stillbirth rates in Tanzania after helping babies breathe training. Pediatrics 2013;131:e353-60. 


\section{MULTIPLE CHOICE QUESTIONS}

\section{Regarding global mortality rates related only to labour and delivery:}

a) There are over one million maternal deaths annually

b) The most frequent clinical cause of maternal death is obstetric haemorrhage

c) Annual numbers of maternal deaths increased between 1990 and 2010

d) The most frequent cause of stillbirth is traumatic breech birth

e) In Africa, annual numbers of neonatal deaths increased between 2000 and 2010

Answers to Question 1: a) F, b) T, c) F, d) F, e) F

\section{Explanations:}

a) F: Global annual maternal deaths from labour and delivery are falling - from 137700 in 1990 to 91100 in 2010, which also represents a fall in cause-specific maternal mortality ratio. All-cause maternal mortality declined from 359000 to 255000 in the same period.

b) $\mathrm{T}$ : Intrapartum and postpartum haemorrhage together made up $56 \%$ of labour-related maternal deaths in the recent WHO systematic analysis. In South Africa, the most common cause was haemorrhage after caesarean section. Probably, wherever on looks in low-and middle-income countries, haemorrhage is the dominant cause for deaths relate to labour and delivery.

c) F: The explanation is the same as for a) above.

d) F: Traumatic breech birth makes up only a small percentage of labour-related perinatal deaths. The most common 'cause' is the rather vague category of 'intrapartum' asphyxia, characterised by fetal or neonatal death in the absence of a catastrophic 'sentinel' event.

e) F: Annual numbers of neonatal deaths decreased in Africa as they did worldwide, but the decline was only $1.1 \%$ annually, compared with the worldwide $2.4 \%$ annual reduction. 


\section{Caesarean delivery has the potential to save lives but safety remains an issue. Ways to achieve}

this include:

a) Reducing the caesarean section rate to about $5 \%$ in low-resource settings

b) General rather than spinal anaesthesia is the technique of choice

c) Non-physician providers such as clinical officers or surgical technicians can undertake these procedures

d) Antibiotic prophylaxis must be routinely given at all caesarean sections, irrespective of whether they are emergency and elective procedures

e) latrogenic fistula following caesarean section is a random event that may occur even after procedures undertaken by experienced surgeons

Answers to Question 2: a) F, b) F, c) T, d) T, e) F

\section{Explanations:}

a) F: Caesarean section rates of around 5\%, such as are found in Malawi, are likely too low to provide best opportunities for reducing maternal and perinatal mortality rates. Recent ecological studies suggest that the ideal caesarean section rate is probably between $10 \%$ and $20 \%$.

b) F: Spinal anaesthesia is the technique of choice, to avoid aspiration pneumonia and uncontrolled hypertension. However, spinal anaesthesia should not be used if the anaesthetic provider is unable to manage the airway (intubate) should there be a respiratory arrest.

c) T: Studies, mainly from south-eastern Africa, have shown that task shifting of caesarean section to non-physician surgeons can be successfully and safely implemented.

d) T: Intravenous antibiotic prophylaxis must be given at all caesarean sections whether emergency or elective. This is supported by evidence of reduced postpartum infections in treated women, from numerous randomised trials. 
e) F: injury including iatrogenic fistula is a consequence of inadequate surgical skill and can largely be prevented by training and certification of competencies.

\section{Principles of high dependency unit (HDU) care for very sick obstetric patients include the}

\section{following:}

This model of care is appropriate for patients requiring ventilation or inotropic support

a) Newborn babies should not be allowed into the unit

b) Key minimum equipment for an effective HDU include pulse oximetry, a sphygmomanometer, access to oxygen and ability to measure urine output

c) Patient flow should be managed so that discharge from the HDU is to home rather than to a postnatal ward

d) This model of care cannot be feasibly offered in low-resource settings

Answers to Question 3: a) F, b) F, c) T, d) F, e) F

\section{Explanations:}

a) F: Standard ICU care is needed for these patients. High dependency units are intended for the majority of 'very sick obstetric patients', who should not require mechanical ventilation, invasive haemodynamic monitoring and inotropic support.

b) F: HDU care can allow mothers and babies to be nursed together and facilitate breast feeding initiation.

c) T: The ability to undertake adequate circulatory and respiratory monitoring and manage fluid balance are of prime importance. Oxygen is needed even where ventilation is not required as patients often have a reduced level of consciousness, may have lost blood or have respiratory compromise owing to sepsis. 
d) F: HDU care fills an intermediate care position between ICU and routine ward care and 'step down' arrangements are required for efficient patient flow. Women who are almost well enough to go home should not occupy beds in a HDU.

e) F: HDU offers life-saving care to women in low-resource settings, where they might otherwise succumb to neglect, for example in crowded postnatal wards with healthy mothers. The numbers of beds, staffing and technologies required are not excessive.

\section{In best practice resuscitation of term newborns who have a bradycardia or are not breathing} normally at birth:

a) Start positive pressure ventilation using $100 \%$ oxygen

b) Give chest compressions using the two-thumb method rather than the two-finger method

c) Give chest compressions at a ratio of 15 compressions to 2 ventilations

d) Use the umbilical vein for giving fluid and medication if needed

e) Discontinue life-saving efforts if there is no detectable heart rate after 10 minutes of resuscitation

Answers to Question 4: a) F, b) T, c) F, d) T, e) T

\section{Explanations:}

a) F: Room air ( $21 \%$ oxygen) is preferred in starting positive pressure ventilation. Use of pure oxygen (100\%) is associated with neurocellular damage and poor clinical outcomes. Pure oxygen blended with air may be given, guided by oximetry readings.

b) $\mathrm{T}$ : The two-thumb method has been shown in low-quality evidence from randomised trials to be associated with increased blood pressure generation, and less compressor fatigue.

c) F: The correct compression: ventilation ratio is 3:1. In newborn resuscitation, asystole or severe bradycardia is primarily a reaction to hypoxia rather than to a cardiac event. 
d) T: The umbilical vein is the vascular access route of choice. Intraosseous infusion is acceptable as a temporary route for vascular access where umbilical vein access is not possible or feasible.

e) $\mathrm{T}$ : In general, discontinuing resuscitation efforts in such circumstances (effectively a 10-minute Apgar score of zero) is reasonable, given the high likelihood of subsequent early mortality (50\%) or moderate to major long-term disability (25\%). The decision can however be individualised. 
Table 1. Clinical obstetric causes of labour-related maternal and perinatal deaths, from national multi-facility audits in South Africa.

\begin{tabular}{|l|l|l|l|}
\hline \multicolumn{2}{|l|}{ Maternal deaths [4] } & Perinatal deaths [11] & $\begin{array}{l}\text { Cause- } \\
\text { specific } \\
\text { PNMRt }\end{array}$ \\
\hline Cause & $\begin{array}{l}\text { Cause- } \\
\text { specific } \\
\text { MMR* }\end{array}$ & Cause & \\
\hline Haemorrhage: & & & 29.4 \\
Bleeding during or after CS & 8.8 & Non-specific 'intrapartum asphyxia' & 5.8 \\
Uterine rupture - previous CS & 2.1 & Cord around the neck & 4.2 \\
Uterine rupture - no previous CS & 2.0 & Cord prolapse & 2.0 \\
Atonic uterus after vaginal birth & 2.0 & Traumatic breech birth & 0.5 \\
Retained placenta & 1.7 & Traumatic assisted delivery & 0.4 \\
Cervical trauma & 0.8 & Precipitate labour & \\
Vaginal trauma & 0.2 & & \\
Uterine inversion & 0.2 & & \\
Sepsis: & 4.6 & & \\
After vaginal birth & 3.4 & & \\
After CS & & & \\
\hline
\end{tabular}

$\mathrm{CS}=$ caesarean section

*MMR = facility-based maternal mortality ratio per 100000 live births 2011-2013; denominator = 2526387

+PNMR = perinatal mortality rate per 10000 births 2000-2003; denominator $=462348$ 
Table 2. Clinical perspective on commonly encountered potentially lethal hazards for childbirth and their mitigation

\begin{tabular}{|c|c|c|}
\hline Hazard & Consequences & Mitigation in low-resource settings \\
\hline Unsafe surgery & $\begin{array}{l}\text { Bladder or bowel injury, iatrogenic } \\
\text { fistula, injury to the fetus }\end{array}$ & $\begin{array}{l}\text { Graded surgical training and } \\
\text { certification of competencies. } \\
\text { Operating theatre checklist. }\end{array}$ \\
\hline Unsafe anaesthesia & $\begin{array}{l}\text { Aspiration pneumonia, cerebral } \\
\text { haemorrhage from uncontrolled } \\
\text { hypertension, cardiac arrest, total } \\
\text { spinal anaesthesia }\end{array}$ & $\begin{array}{l}\text { Spinal anaesthesia as standard of care } \\
\text { for caesarean delivery. Graded } \\
\text { anaesthesia training and certification } \\
\text { of competencies. Operating theatre } \\
\text { checklist. }\end{array}$ \\
\hline $\begin{array}{l}\text { Uncontrolled severe pre- } \\
\text { eclampsia/eclampsia }\end{array}$ & $\begin{array}{l}\text { Cerebral haemorrhage, aspiration } \\
\text { pneumonia, coagulation failure, } \\
\text { organ failure }\end{array}$ & $\begin{array}{l}\text { Access to magnesium sulphate and } \\
\text { antihypertensives, management of } \\
\text { fluid balance (Chapter } 7 \text { ) }\end{array}$ \\
\hline Sepsis & $\begin{array}{l}\text { Endometritis, wound sepsis, } \\
\text { peritonitis, septicaemia, neonatal } \\
\text { sepsis }\end{array}$ & $\begin{array}{l}\text { Prevention: delivery and surgical } \\
\text { hygiene practices, correct tissue } \\
\text { handling, prophylactic antibiotics. } \\
\text { Treatment: timely surgery to remove } \\
\text { focus of infection, parenteral } \\
\text { antibiotics (Chapter 9). }\end{array}$ \\
\hline $\begin{array}{l}\text { Major obstetric } \\
\text { haemorrhage }\end{array}$ & Cardiac arrest, organ failure & $\begin{array}{l}\text { Prevention and emergency treatment } \\
\text { (Chapter 6) }\end{array}$ \\
\hline Uterine rupture & Major haemorrhage, stillbirth & $\begin{array}{l}\text { Clinical skills to detect abnormal lie } \\
\text { and presentation in labour. } \\
\text { Application of partograph. Adherence } \\
\text { to correct use of oxytocin and } \\
\text { misoprostol. Surgical skills to arrest } \\
\text { bleeding. }\end{array}$ \\
\hline $\begin{array}{l}\text { Delayed detection or } \\
\text { response to fetal } \\
\text { bradycardia }\end{array}$ & $\begin{array}{l}\text { Stillbirth, hypoxic ischaemic } \\
\text { encephalopathy }\end{array}$ & $\begin{array}{l}\text { Intrapartum fetal heart rate by } \\
\text { Doppler or CTG. Competencies in } \\
\text { instrumental delivery. Access to } \\
\text { operating theatre for emergency } \\
\text { caesarean section. }\end{array}$ \\
\hline Traumatic birth & $\begin{array}{l}\text { Tentorial tear, fractures, } \\
\text { subaponeurotic haematoma }\end{array}$ & $\begin{array}{l}\text { Skills drills for assisted vaginal birth, } \\
\text { assisted breech birth and shoulder } \\
\text { dystocia (Chapter 5). }\end{array}$ \\
\hline
\end{tabular}


Table 3. Supportive management of babies with hypoxic ischaemic encephalopathy

\section{Supportive management in HIE}

Birthing room:

Resuscitation beginning with room air \pm supplemental oxygen if needed

Temperature:

Avoid hyperthermia

Therapeutic hypothermia for eligible infants

Oxygenation and ventilation:

Maintain normal ranges of $\mathrm{PaO}_{2}(60-100 \mathrm{mmHg})$ and $\mathrm{PaCO}_{2}(30-55 \mathrm{mmHg})$

Perfusion:

Promptly treat hypotension: maintain mean arterial pressure $\geq 40 \mathrm{mmHg}$

Avoid hypertension

Fluid and Electrolytes:

Initial fluid restriction

Monitor daily weight and serum sodium level

Maintain blood glucose in normal range $(2.5-8 \mathrm{mmol} / \mathrm{L})$

Prompt correction of coagulopathy and bleeding

Treatment of seizures:

Phenobarbitone and/or phenytoin

Consider benzodiazepines, lignocaine or levetiracetam 